\title{
Project-based Learning Case of Master Students in the Russian North
}

\author{
Maria Druzhinina \\ Dep. of Translation and Applied Linguistics, \\ Northern Arctic Federal University (NARFU), \\ Arkhangelsk, Russian Federation \\ m.druzhinina@narfu.ru
}

\author{
Inga Zashikhina \\ Dep. of English Philology and Language Pedagogy \\ Northern Arctic Federal University (NARFU), \\ Arkhangelsk, Russian Federation \\ i.zashikhina@narfu.ru
}

\begin{abstract}
The article studies a case of project-based learning in Northern Arctic Federal University, Russia. A group of master students studying Chinese was given a task to develop a topical research project in the field of higher education that would be useful for their professional development. The students choice of the project area was internationalization, namely students academic mobility. The interest was determined by increasing mutual interest of Russia and China in interaction in economic, political and cultural fields. The main aim of the project was to establish contacts with Chinese universities in order to organize programmes of academic mobility for students. The participants studied the educational system of China and selected thirty universities which they wanted to build relationships with. More than fifty letters of academic correspondence were written in the course of project work. The outcomes of students collaboration have been analysed by the project supervisors in this paper.
\end{abstract}

Keywords-project-based learning, university education, master programme, professional competences, internationalization

\section{INTRODUCTION}

Project-based learning, development and implementation of educational as well as research projects have acquired a considerable importance in the international educational space, in scientific and educational practices of various specializations and levels. Numerous scientific reports and research articles suggest evidence of extensive use of the project method for a wide range of undergraduate and graduate educational programmes in all training directions of higher education - social, humanitarian, science, engineering and technical [1-3]. Implemented projects are interdisciplinary $[4,5]$ and often international $[6,7]$. This fact is explained by the growing motivation of teachers and students from different countries to take part in global international academic mobility and to cooperate with scholars in relevant scientific research of various professional and academic background. The project method is known for its high potential in building students' general cultural, professional and research competences, and therefore has won a special status in the realization of all disciplines of the curriculum [8, 9]. In this relation, it is also worth noticing that according to the international demands for curriculum design, the conceptual idea of ongoing projectbased learning of master students is vastly developed [10].
In this article, the authors would like to share their experience of the case of project-based learning, which took place at Norther (Arctic) Federal University, Arkhangelsk, the Russian Federation, within master programme «Professional Communication in the Eurasian Context». To accumulate knowledge of project method use in university settings, the authors have analyzed the following questions:

1. How is project-based learning used for master students?

2. Which of the achievements of global education in the area of project-based learning should be continued in NARFU's master programmes?

3. What are the most efficient ways of project development, implementation and evaluation within master programmes?

The three mentioned-above issues have made the basis for this research. To reach the aim of the present study, a whole number of specific points addressed in international academic publications have been investigated. Among them there are problems of project management, types of projects, approaches to project work, stages of project implementation, evaluation of cooperative project work, students' competence development within project-based learning, knowledge transfer in project-based learning and other features of project method use in the educational space [1-14]. The hermeneutical analysis of academic literature on the topic, critical reflection on shared professional experience of the authors as well as their professional discussions on the related issues of projectbased learning have resulted in:

1. theoretical analysis of scientific literature sources on project-based learning;

2. development and organisation of authors' professional conceptual ideas in the area of project-based learning/ teaching of master students;

3. analysis of practical results of master students' cooperative project work within the curriculum.

The authors' research incorporates the features of Northern territories of the Russian Federation, which are a factor always taken into consideration during the design of master programmes of NARFU. This factor means that NARFU's 
master students are prepared to implement massive complex and demanding cross-cultural international projects in their future professional lives. NARFU's master programmes focus on active project-based learning, which enables formation of professional skills demanded in the Arctic zone, i.e. key general cultural and professional competences, enlisted in the modernised Federal state educational standards and NARFU's Development Programme [17, 18].

\section{LITERATURE REVIEW}

Project-based learning has been defined in many international academic publications which has resulted in the relevant abbreviation PBL [5]. The data on PBL phenomenon represented in present-day scientific sources give evidence of the fact that project-based approach to education is being developed actively in the contemporary educational space [2, 6 , 7]. New methodology, set of conceptual ideas, content, organisation, techniques and forms of project work, the trajectory of movement towards expected results of the project, evaluation methods, etc. are all subjects of vivid scholarly discussions and critical scientific investigation [19, 20]. Growing interest towards project work among university students of various academic fields and levels can be acknowledged [see 1-20]. The authors have analysed more than 50 research publications and summarized the main directions of the international academic research on projectbased learning in higher education. They are the following:

1. methodology of project work in education,

2. types of projects and methods of project work,

3. project-based learning in virtual space and e-learning,

4. project work organisation (stages, content and techniques of project implementation),

5. key and professional competences formation,

6. transfer of knowledge acquired in the process of project-based learning into professional activities,

7. ensuring innovative attractiveness of project-based learning,

8. search of unique work methods and successful presentations techniques of project work results,

9. evaluation methods of project work, etc.

Taking into account the data of the analysed academic publications, the authors selected the following educational goals for the case of project-based learning described later in this article:

building marketable professional competences;

fostering construction of the learner's trajectory from the aim of the project to its results;

enhancing innovative attractiveness of project work for the students;

ensuring clear and effective feedback and evaluation of the project work; promotion of knowledge transfer and further development of the project for professional purposes.

\section{RESEARCH METHODOLOGY}

Project-based learning is a common feature of NARFU's master programme «Professional Communication in Eurasian Context». It is one of the core teaching methods during all the four academic semesters and is used in the course of laboratory classes, professional training periods and in the process of master thesis preparation. Thus project work is performed in three directions of students' studies:

1. for field-related educational purposes and as a method of knowledge transfer and building professional competences during academic semesters;

2. in professional training periods to design real-life models of future work-related situations;

3. for research purposes through the whole period of master studies (master thesis preparation).

This paper is focused on the students' collaborative project named «Student Academic Mobility». The project work was offered to a group of 15 students as a a part of the module «English for Professional Communication» during the first semester of their master studies. Initially students had a task to design a real-life group project which deals with a problematic situation in the field of their academic research and/ or profession (Linguistics). Students were explained that the task they received was an open one. The last point was essential as the teachers' aim was to see how well the students can plan their professional development and see their future. They were to choose from the range of problems interesting for all members of the project team. A sample algorythm of collaborative work was suggested:

4. Choose the specific issue you would like to develop.

5. Discuss the participants' suggections, listening to voices.

6. Choose the leader of the project group.

7. Develop a plan of actions and come up with parts of the future project.

8. Work out a timetable with deadlines and points of meetings.

9. Work at each part of the project one by one, discussing them and drafting the report of the project.

10. Develop the project, make changes and additions according to the resolutions taken by all membrers of the project group.

11. Make a ppt presentation of the project.

12. Edit the final version of the project report.

13. Discuss the work you have done and feelings you experienced in the process of your work. Make conclusions and share ideas for future research and collaboration.

There was also a list of conditions to follow in the course of the project work, which ran as follows: 
- The statement and results of the project have to correspond to administrative documents and norms, as well as theoretical postulates of the modern researchers in the area. References following the standard of NARFU are to be presented.

- Results of the project have to be of practical, theoretical and educational importance for the project group and the university in general. In the course of project work, research methods are to be applied. Critical thinking and inquiry method are vital for analysis.

- Content of the project is to follow a strict structure; each part of the plan having its own results, that are presented in the report.

- Each group member's participation is essential. Listening to voices and tolerance are part and parcel of the project work. Work loads are to be distributed among group members. Project leadership belongs to the member of the group, chosen on agreement between all group members.

Evaluation criteria of the project work were also announced. They included those related to the quality of research work and those that measured the level of group collaboration:

- well-formulated goal and objectives, grounded research methodology;

- $\quad$ full presentation of the chosen issue;

- multi-faceted discussion of the data;

- $\quad$ high-quality analysis;

- balanced, well-grounded and meaningful conclusions, which correspond to the objectives of the project;

- up-to-date literature and bibliography referencing;

- $\quad$ layout of the report and ppt presentation;

- $\quad$ level of indepent thinking and work fulfillment.

Team work assessment criteria presented to the students included:

- novelty and relevance of ideas and suggestions;

- $\quad$ leadership and group organization;

- $\quad$ collection and analysis of data;

- $\quad$ report preparation;

- $\quad$ presentation preparation.

Experimental project work was divided into three stages: 1) the preparatory stage, 2) the main stage, and 3) the concluding stage. The first stage involved a lot of discussions which aimed at the discovery of students' personal and professional interests, their module expectations, areas of particular urgency in terms of social, economic and cultural situation in the contemporary education and labour market. They were followed by disputes aimed at planning of the future project. Project's content and structure, forms of team work were negotiated and resources were allocated. The second stage was devoted to the realisation of the designed project. The third stage implied the presentation of project's results. It also included evaluation of the project work on the part of both the students and two supervisors of the group work (authors of the present article).

\section{GROUP PROJECT DESCRIPTION}

Master programme «Professional Communication in Eurasian Context» among other aspects accomodates studying of the Chinese language for professional purposes, which is one of the main assets of the programme. Many applicants admit that acquisition of Chinese makes the programme attractive for them. They also confess that travelling to China for personal and professional purposes is among their priorities. These factors defined the choice of the research field by the students. Academic mobility among students was selected as the topic of the collaborative project. The main object of the project work was described as a constant development of actions aimed at durable partnership with Chinese universities. The process of building relationships with Chinese universities with its singularity and difficulties was considered a subject of the project work.

The students' interest to the project was determined by increasing mutual interest of Russia and China to interact in economic, political and cultural fields. Success of the educational programme "Professional Communication in Eurasian Context" in the field of "Linguistics" of the Northern (Arctic) Federal University named after M.V. Lomonosov depends on the ability of students, lecturers and professors to gain experience by interacting with native speakers. It would be a benefit for both sides to provide the opportunity for Russian students and lecturers to have internship in a Chinese university to improve their skills of teaching Chinese language and to create conditions for the Russian language teaching in China. The promotion of the students and lecturers' exchange would help them to attend language courses and summer schools. High-level professional communication experience, intensive language training, acquaintance with partner country culture and customs were conceived as the advantages of such interactions and the project itself. The opportunity to obtain a double diploma of education as a result of studies at the Chinese and Russian Universities was also a desired goal.

The main aim of the project was set to establish contacts with Chinese universities in order to organize programmes of academic mobility for students. To achieve this, a number of tasks were planned to accomplish:

1. to collect information about Chinese universities, focusing at the university departments of Linguistics and programmes connected with learning Russian as a foreign language;

2. to compose a letter of proposal both in Chinese and English containing description of the programme and suggestion of professional relationship;

3. to send the letter via email to a wide variety of Chinese universities: 
4. to process the expected responses and develop the perspective of possible contacts.

The expected outcomes of successful project work were the formation of the following competences:

- communicative competence (well-developed language skills, the ability to take part in oral and written communication),

- professional competence (ability to analyse information in a foreign language, ability to work in a team of professionals, creative fulfillment),

- $\quad$ another outcome was internationalisation of NARFU master students' education (academic mobility, professional cross-cultural communication development, transfer of knowledge into other fields of activities, e.g. international projects).

The outcomes were measured and compared according to a three-level scale: low (less than 50\%), medium $(50-80 \%)$ and high (more than $80 \%$ ). Each indicator was added up and the arithmetic average result was calculated.

The project work continued during the whole semester within the curriculum of the academic module "English for Professional Communication". The curriculum included 86 practical hours and 238 hours of independent students' work and equalled 10 ECTS. In the academic programme, the module is a compulsory one. Mostly the studies in the module are conducted in a traditional mode (60 academic hours of practical work). The rest of the workload (26 academic hours of practical work and 100 hours of independent work) is fulfilled online. Students and supervisors of the project work met each other for face-to-face sessions of English weekly. Project work was conducted online unless students expressed their willingness to discuss issues related to the project in class. In that case supervisors welcomed dialogue and fostered exchange of ideas, guided debates and provided consultations. Online work was carried out on the platform of learning management system (LMS) Sakai, which is an official LMS of NARFU. Students have had a rich experience of online learning with the help of Sakai platform and can efficiently use its communication features like chat room, forum and text exchange. These were the main communication instruments through which project work was implemented. Students also used Google Docs and Google Disc applications for writing, editing and exchange of text files.

\section{RESEARCH RESULTS}

\section{Professional development and career}

Student academic mobility is normally provided with the help of educational funds, state organisations interested in innovations, business companies, etc. As a rule, students are given information about academic mobility programmes by their teachers or they may find information on NARFU site. However, nowadays grants are mostly offered to those students who study science, biology, physics, engineering, information technologies, etc. Humanitarian fields of research, e.g. linguistics, are not so often funded by the state and profit organisations. Besides, requirements to grant applicants are so demanding, that very few students find capacities to meet them. That is why the students' choice of topic for the group project caused deep satisfaction among the supervisors. It showed that students realised the importance of internationalisation in the area of education and expressed readiness to work at their own academic mobility. Besides, they were aware of the fact that to become successful professionals and acknowledged researchers they had to receive a wide range of knowledge in their academic field. As Chinese was a core subject in their curriculum, they knew they were to have a good command of the language. Natural environment and authentic communication are vital for language acquisition. Overall, students' analysis of the opportunities, factors of success, demands of the labour market in their professional field turned out to be reasonable and well-grounded.

\section{Project work organisation and project management}

From the start of the project work, a hands-off approach was adopted. Students were given freedom in their decisions and actions. At the same time, continuous feedback and teachers' support were offered. During the preparatory stage of the project work, many questions were asked by the students. The inquiries were of organisational nature and related to the essence of the research, e.g., Should the project work be discuss face-to-face or via electronic means of communication? Should human imagination be used or real numbers should be taken from the available sources? What would be the outcome of this project? How long should the report be? However, gradually questions became more specific and showed that the preparatory stage passed successfully. The students came to agreement with regard to the aim, scope and expected results of their project.

In the process of project work students expressed concerns about some participants' input into the research activities, because quite early it became clear that not all students were willing to put their efforts into project tasks. In fact, $20 \%$ of the participants preferred to remain disinterested and passive. On the other hand, five students (35\% approximately) stood out for their leadership and research activities. The rest of the students fulfilled the tasks they were allocated with at a fairly good level. Students examined Internet sources which contained information on education in China, including university sites. As a result, web resources of 30 Chinese universities were investigated and systematised. Educational models and opportunities for internationalisation were viewed from the perspective of five main characteristics of modern universities: general information, location, international programmes and modes of studies, scholarships for international students, availability of contact details. It turned out that some of the universities did not provide information in English and the students had to apply for help of a Chinese teacher, a member of NARFU's professor staff. More than 50 letters of academic correspondence were written at that period. During the main stage of the project, students made some discoveries relating to the national features of education in China and those characteristics of Chinese education which they found in common with Russian education. They also showed deep satisfaction with their job when letters they sent to the Chinese universities received answers. Mostly, the 
feedback was positive. Chinese universities shared information on summer schools and opportunities of education for international students. By the end of the project period students had some prospective opportunities of academic mobility. Three of the chosen universities encouraged the project participants to engage in their international projects or come with academic visits and offered opportunities for residence and studies. There were also letters which did not receive any feedback.

The concluding stage revealed problematic areas of communication among students. Some of the participants caused deep disapproval of the project team because of their lack of determination and academic diligence. Students also needed encouragement and support, since energy levels and personal motivation were noticeably lower than at the beginning of the project, which manifested in late responses to the supervisors' letters inquiring about the project's progress. Nevertheless, closer to the project's deadline a written report draft was prepared and sent for the teacher's approval. After editing, the report was typed on 80 pages and contained all the information relating to the project, including students' evaluation of the project work. They assessed their group collaborations as «interesting», «fascinating», «absorbing» and «innovative». They also agreed on a lack of knowledge of the Chinese language and showed high motivation in Chinese studies. Students also expressed their wish to travel to China, even if at their own expenses.

\section{Academic outcomes and education} internationalisation

The survey offered to the students at the end of their project work, project report, students' presentation of the project results, as well as the concluding discussion with the project supervisors and students showed the following results:

- Communicative and language competence grew from A 2 to B1 level (60\% of the students)/ B2 to C1 (40\% of the students).

- Quality of creative work in the experimental group grew by $60 \%$.

- Student mobility/ education internationalisation boosted by $80 \%$ in the target group.

\section{Students' empowerment and confidence growth}

Academic mobility, according to the results of the survey held during the concluding stage of project work, had always caused uneasiness and concern among students (95\% of the student group). Knowing that academic mobility is an important factor of academic success, students put it in the list of their priorities ( $80 \%$ of the student group). However, they did not see any accessible instruments to take part in the programmes of academic exchange or in international academic projects. The reason for the lack of opportunities to enroll into academic exchange programmes was primarily connected with the fact that there is little information on exchange programmes with Chinese universities. The other significant factor is that student exchange programmes usually require co-financing, and personal financial input is a prerequisite. To add to this list, one also needs to notice that at
NARFU, there are no well-established traditions of academic communication with eastern universities.

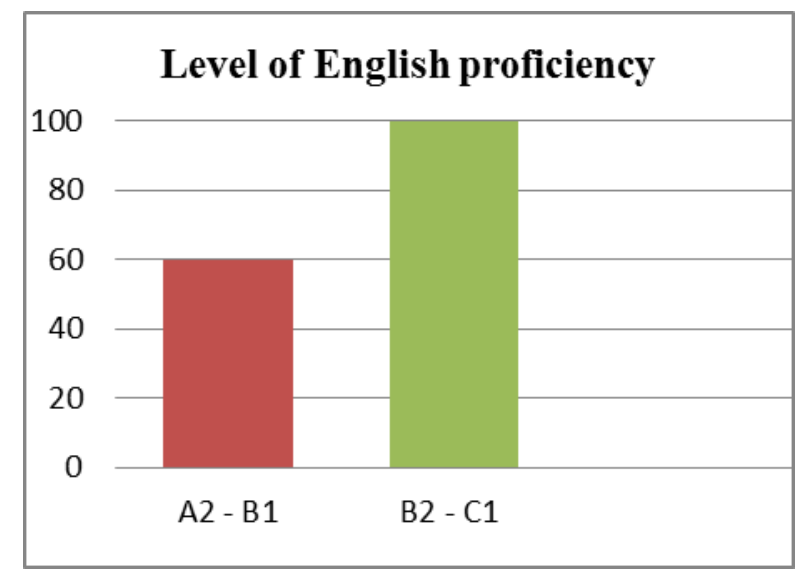

Fig. 1. Students' language proficiency level on completion of the experiment

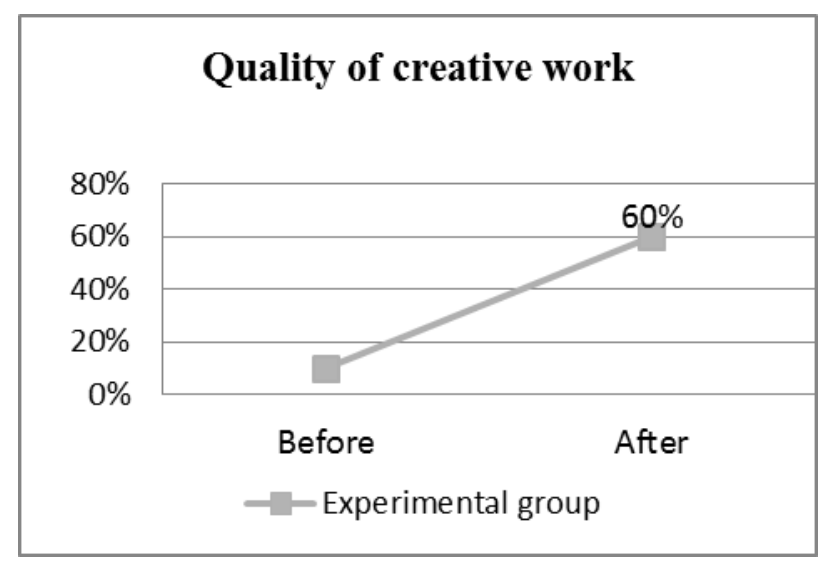

Fig.2. The quality of students' creative works on completion of the experiment

\section{Growth of internationalization}

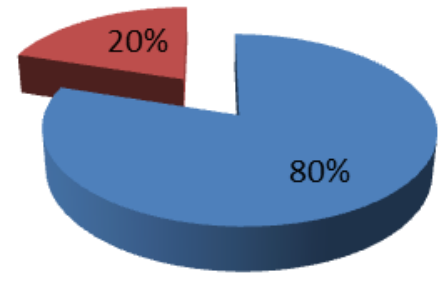

Fig. 3. 80\%-growth of internationalisation (students' mobility, participation in international projects and knowledge-transfer to the other international projects)

An outstanding result of the project was revealed when the authors got the answers to the questions of the survey which were meant to measure students' readiness for further international collaboration and feelings of self-confidence in relation to the capacities for internationalisation of their education. These were questions: 
- $\quad$ Have you ever taken part in any other international projects at NARFU or other educational establishments?

- What feelings did you have in relevance to the project in the beginning of the semester/ before the group started developing the project?

- What were your expectations in terms of the project's outcomes?

- Did the outcomes of the project work coincide with your expectations of them?

- What part of your project work turned out to be the most appealing for you?

- What part of your project work turned out to be the most challenging for you?

- Has your attitude towards international projects altered in the course of your work? Please, explain, how.

- Would you like to take part in any other international projects? Which?

- How are you going to develop your education internationalisation? Please, describe the possible steps in this direction.

- What initiatives would you suggest to NARFU relating to student academic mobility and education internationalisatoion?

Students' answers showed that only a small part of the project participants had taken part in international educational activities before. The whole idea of academic internationalisation had been vague for them. They were not confident of what they could have done to increase the level of engagement in international academic activities. Moreover, when the students started the project work, most of them ( 82 $\%)$ did not have any anticipations at all. The initial stage of the project was generally facilitated by the project supervisors. What was clear and apprehensible was such instrumental activities as search for information in the world wide web and writing letters to Chinese universities. These were also the procedures that the students enjoyed more. They also explained that the most positive part of the project happened closer to the end of it. That was the period when they started getting responses from prospective partners. One can deduce that positive results the students achieved in the course of studies inspired them to continue the task that had not been obvious nor comprehensible enough for them. They did cope with the tasks which they had done before (information search, academic correspondence writing). At the same time, one could see that the logic of project work had not been visible for the majority of the participants. The mechanisms and perspectives of academic internationalisation had been equally dim. That is why the development of the project's structure and prediction of work consequences had turned out to be such a demanding assignment. Active approach and reallife experience have been the main pedagogical methods to improve the situation. The respondents of the survey showed their willingness to proceed with international work in the area of education. They admit that when the results of their project work had become tangible, they grew more motivated in terms of such activities. Among students' plans, there are grant applications, volunteering activities and publishing in international journals. They also suggest that NARFU would 1) organise international summer schools in collaboration with local students; 2) promote students' publishing and help them to become successful at it; 3) collaborate with eastern universities as purposefully as with western universities.

\section{CONCLUSIONS}

To sum it up, the results of the students' project work have revealed huge potential of this kind of academic work with master students. The effectiveness of general cultural and professional competences formation has shown a serious improvement (more than 40\%). Education internationalisation has been actualized by $80 \%$ participation of the students in the university international activities, chiefly in the project implementation. Knowledge received by the students in the course of the project-related activities is transferrable and can be applied to other international collaborative projects.

Project implementation has disclosed the following perspectives of the future international collaboration in the following areas:

1. collaborative work of the project participants with the Department of International Affairs of NARFU regarding the establishment of solid contacts and successful communication with Chinese universities' Departments of International Affairs;

2. invitation of Chinese universities to participate in NARFU events arranged for foreign students and teachers (e.g. Summer and Winter Schools, Student Exchange Programme);

3. participation of NArFU students in international programmes suggested by universities of China, during the course of which they can learn Chinese and culture, visit famous sights and cities of China and make contacts;

4. providing opportunities for Chinese students to learn about history and culture of the Russian North, Arctic and Russia on the whole and to visit historical places.

\section{References}

[1] M. Balkevičius, A. Mažeikienè, S. Švedienè, "The first steps of projectbased education in Lithuanian high schools," Procedia - Social and Behavioral Sciences, No. 83, pp. 483-492, 2013.

[2] E. Jaleniauskien, "Revitalizing Foreign Language Learning in Higher Education Using a PBL Curriculum," Procedia - Social and Behavioral Sciences, No. 232, pp. 265-275, 2016.

[3] S. Belda-Miquel, J. P. Blanes, I. C. Fernández, "Participation for transformative learning in development management: The case of a Master in international development projects in the Universitat Politècnica de València (Spain)", Procedia - Social and Behavioral Sciences, No. 228, pp. 237-242, 2016.

[4] R. Pucher, M. Lehner, "Project Based Learning in Computer Science. A Review of More than 500 Projects", Procedia - Social and Behavioral Sciences, No. 29, pp. 1561-1566, 2011.

[5] I.-B. Păvăloiu, I. Petrescu, C. Dragomirescu. "Interdisciplinary ProjectBased Laboratory Works," Procedia - Social and Behavioral Sciences, No. 180, pp. 1145-1151, 2015. 
[6] T. Voronchenko, T. Klimenko, I. Kostina, "Learning To Live In A Global World: Project-Based Learning In Multicultural Student Groups As A Pedagogy Of Tolerance Strategy," Procedia - Social and Behavioral Sciences, No.№ 191, pp. 1489-1495, 2015.

[7] R. Ciutiene, E. Meiliene, "Main Factors Influencing Efficient Planning Of International Projects: Sample Of High Schools International Projects," Procedia - Social and Behavioral Sciences, No. 191, pp. 15061516,2015

[8] F.-J. Arroyo-Cañada, A.-M. Argila-Irurita, M.-L. Solé-Moro, "Competency-based learning in a real and multicultural marketing consultancy project," Procedia - Social and Behavioral Sciences, No. 228, pp. 449-456, 2016.

[9] P. Supadol, W. Sukreeyapong, P. Intarakumhaeng, K. Siripan, W. Chantanapim, N. Nesusin, "Results of Learning Activities of Grade 1 Thai Language Subjects Using the Project-Based Approach,” Procedia Social and Behavioral Sciences, № 116, pp. 1444-1448, 2014.

[10] Tuning educational structure in Europa. Reference Points for the Design and Delivery of Degree Programmes in Linguistics. Tuning Project, Publicaciones de la Universidad de Deusto Apartado 1 - 48080 Bilbao, 2012.

[11] Z. Kem'enya, R. J. Beregia, G. Erd"osa, J. Nacsa, "The MTA SZTAKI Smart Factory: platform for research and project-oriented skill development in higher education,” Procedia CIRP, № 54, pp. 53-58, 2016.

[12] L. Crawforda, B. Lloyd-Walkerb, E. Frenchc, "Career Choice and the Experience of Project-Based Work," Procedia - Social and Behavioral Sciences, № 194, pp. 55-64, 2015.

[13] M. S. Saltymakov, E. O. Frantcuzskaia, «Cooperative Learning Approach to Delivering Professional Modules to Bachelor and Master
Students: TPU Experience," Procedia - Social and Behavioral Sciences, No. 215, , pp. 90-97, 2015.

[14] F. Fatkullina, E. Morozkinaa, A. Suleimanova, "Modern Higher Education: Problems and Perspectives," Procedia - Social and Behavioral Sciences, No. 214, pp. 571-577, 2015.

[15] M. Druzhinina, "Transfer of knowledge from the course "Company German" to project work in the workplace (using the example of the presidential program for managers and business people)," Transfer of knowledge between research, education and business: international conference. Archangelsk, 2015.

[16] N. Kukarenko, I. Zashikhina, Internationalisation the Russian Way: Modernization of the Higher Education System in Russia in Higher Education in the High North. Academic Exchanges between Norway and Russi, Springer, 2017, pp. 21-46.

[17] Federal State Educational Standarts of RF in Linguistics.Order of the Ministry of Education and Science of Russian Federation №783, 2016.

[18] Programme of Development of Federal State Autonomous Institution of Higher Professional Education «Northern (Arctic) Federal University» for the period of $2010-2020$. Arkhangelsk, NARFU, 2009. Updated in 2015. URL: http://narfu.ru/upload/medialibrary/df9/1604_r_programmarazvitiya-safu.pdf.

[19] V. Serikov, V. Pichugina, N. Saurenko, "Project Approach as the Methodology of Constructing the Content and Technology of University Education," Procedia - Social and Behavioral Sciences, No. 214, pp. 399-406, 2015.

[20] J. Sykorova, "Outputs of interactive exploration and project-based teaching at Mendel University in Brno, Czech Republic," Procedia Social and Behavioral Sciences, № 174, pp. 3224-3227, 2015. 